\title{
Association of IL4 rs2070874, FoxP3 rs3761548 Polymorphisms with Keratoconus in Algeria
}

\author{
Wafaa Meteoukki ${ }^{1,2}$, MS; Mostefa Fodil ${ }^{2,3}$, PhD; Nawel Adda Negaz ${ }^{2,4}$, MD; Nesrine Rahmoun ${ }^{1}$, PhD \\ Sarah Lardjam Hetraf ${ }^{1}$, PhD; Hadjira Ouhaibi Djellouli ${ }^{1}$, PhD; Ahlem Djelti Messal ${ }^{1}$, PhD; Meriem Abdi ${ }^{1}$, PhD \\ Meriem Samia Aberkane ${ }^{1}$, PhD; Abdelillah Chiali ${ }^{4}$, MD; Amine Derdour ${ }^{5}$, MD; Aicha Idder ${ }^{2,5}$, MD \\ Faouzia Zemani-Fodil ${ }^{1,2}$, PhD \\ ${ }^{1}$ Laboratoire de Génétique Moléculaire et Cellulaire (LGMC), Université des Sciences et de la Technologie d’Oran Mohamed \\ BOUDIAF- USTO-MB, BP 1505, El M'naouer, 31000 Oran, Algérie \\ ${ }^{2}$ Agence Thématique de Recherche en Sciences de la Santé (ATRSS)- Oran, Algérie \\ ${ }^{3}$ Ecole Supérieure des Sciences Biologiques d'Oran (ESSBO) \\ ${ }^{4}$ Clinique Chiali, Oran, Algérie \\ ${ }^{5}$ Laboratoire de Génétique Médicale Appliquée à l’Ophtalmologie, Clinique Hammou Boutlélis Oran, Algérie
}

ORCID:

Wafaa Meteoukki: https://orcid.org/0000-0001-9821-5808

\section{Abstract}

Purpose: The aim of this case-control study was to determine the impact of environmental factors on the predisposition to develop keratoconus in a sample of Western Algerian population. Subsequently, we were interested in the implication of two single nucleotide polymorphisms (SNPs) IL4 rs2070874 and FOXP3 rs3761548, previously described as contributing to the occurrence of allergy, in the development of keratoconus.

Methods: The study included 70 unrelated $\mathrm{KC}$ cases and 70 controls originating from Western Algeria. DNA genotyping was done using predesigned probe-based allelic discrimination TaqMan $^{\circledR}$ assays. Allele and genotype frequencies were compared between the cases and controls by Chi-square test and odds ratios with 95\% confidence intervals.

Results: A significant association between risk factors such as family history, atopy, eye rubbing, and the development of keratoconus was found in our sample. Smoking would provide a protective effect against the pathology. No statistically significant differences were found in the allele and genotype frequencies between cases and controls neither for IL4 rs2070874 nor for FOXP3 rs3761548.

Conclusion: Our study provides, for the first time, a clear demonstration of the absence of association of the allergy-associated IL4 and FOXP3 polymorphisms with $\mathrm{KC}$ in a sample from Western Algerian population.

Keywords: Case-Control Study; FOXP3 Gene; IL4 Gene; Keratoconus; Polymorphisms; Western Algeria

J Ophthalmic Vis Res 2021; 16 (4): 558-565 


\section{INTRODUCTION}

Keratoconus $(\mathrm{KC})$ is a degenerative bilateral corneal dystrophy characterized by gradual thinning of the cornea leading to a loss of visual acuity. $\mathrm{KC}$ is classified as a noninflammatory disease $;^{[1]}$ however, several studies rejected this theory after the discovery of the expression of inflammatory mediators such as cytokines in the tears of patients suffering from $\mathrm{KC} .^{[2,3]}$

$\mathrm{KC}$ is a multifactorial disease resulting from the interaction of environmental and genetic factors. Although the etiology of KC is not clearly established, genetic and environmental factors such as allergy or eye rubbing seem necessary for disease expression, ${ }^{[4]}$ despite the positive associations found between atopy (allergy, asthma, eczema) and $\mathrm{KC} \cdot{ }^{[5-7]}$ No study has focused on the association between $\mathrm{KC}$ and polymorphisms in inflammatory mediators genes of these immune disorders.

Interleukin 4 is a pleiotropic cytokine produced by activated T-lymphocyte and mast cells. ${ }^{[8]}$ This cytokine plays a major role in type 2 immune responses characterized by the production of immunoglobulin $E(\operatorname{lgE})$ and immunoglobulin $\mathrm{G} 1$ (IgG1). ${ }^{[9]}$ IgE is strongly implicated in atopic and allergic diseases. ${ }^{[10]}$ Several genetic variants in the IL4 gene and its receptor IL4-R have been found associated with allergic rhinitis (AR). ${ }^{[1]}$ The IL4 rs2070874 has been reported as associated with asthma and atopy in several studies. ${ }^{[12,13]}$ HaiJun Yang performed a meta-analysis and found that this polymorphism is correlated with increased asthmatic risk. ${ }^{[14]}$

The Forkhead box transcription factor (FOXP3) has an important role in the development and function of regulatory $T$ cells (Tregs), and also in peripheral tolerance. ${ }^{[15]}$ Many severe lymphoproliferative diseases occur due to Treg

\section{Correspondence to:}

Wafaa Meteoukki, MS. Laboratoire de Génétique Moléculaire et Cellulaire, Université des Sciences et de la Technologie d'Oran Mohamed BOUDIAF- USTO-MB, BP 1505, El M'naouer, 31000 Oran, Algérie.

Email: wafaa.meteoukki@univ-usto.dz

Received: 23-11-2020 Accepted: 15-04-2021

Access this article online

Website: https://knepublishing.com/index.php/JOVR

DOI: 10.18502/jovr.v16i4.9745 deficiencies resulting from FOXP3 mutation. Thus, Tregs mediate dominant tolerance to self and have also been shown to be equally important in the control of autoimmune diseases, allergy, fetal-maternal tolerance, allograft tolerance, and immunopathology. ${ }^{[16]}$ The rs3761548 polymorphism of FOXP3 gene was identified as being associated with $A R$ in heterozygous form in Han Chinese patients, ${ }^{[17]}$ and in Hungarian AR patients. $^{[18]}$

To the best of our knowledge, this is the first study dedicated to the study of $\mathrm{KC}$ in Algeria and Africa in order to find a possible association between the inflammatory gene polymorphisms (rs2070874 and rs3761548) and the disease pathology.

\section{METHODS}

\section{Subjects}

In total, $70 \mathrm{KC}$ cases and 70 healthy controls originating from Western Algeria were included in this study. Patients were recruited from the specialized hospital, Institute of Ophthalmology EHS (établissemnt hospitalier specialisé) Hammou Boutelilis in Oran Algeria as well as from a private ophthalmology clinic. The control group included voluntary donors from the blood transfusion center of Oran hospital "CHUO" (Centre HospitaloUniversitaire d'Oran), as well as student volunteers [Table 1].

The present study was conducted according to the principles set out in the Declaration of Helsinki, ${ }^{[19]}$ and was approved by the ethics committee at the National Evaluation and Planning Committee of the Algerian University Research. An informed written consent was obtained from all participants.

Detection of KC was performed by an experienced ophthalmologist based on visual acuity assessment, findings of slit lamp as: corneal

This is an open access journal, and articles are distributed under the terms of the Creative Commons Attribution-NonCommercial-ShareAlike 4.0 License, which allows others to remix, tweak, and build upon the work non-commercially, as long as appropriate credit is given and the new creations are licensed under the identical terms.

How to cite this article: Meteoukki W, Fodil M, Negaz NA, Rahmoun $\mathrm{N}$, Hetraf SL, Djellouli HO, Messal AD, Abdi M, Aberkane MS, Chiali A, Derdour A, Idder A, Zemani-Fodil F. Association of IL4 rs2070874, FoxP3 rs3761548 Polymorphisms with Keratoconus in Algeria. J Ophthalmic Vis Res 2021;16:558-565. 
Table 1. Study population's characteristics

\begin{tabular}{lccc}
\hline Characteristics & KC cases (\%) & Healthy controls (\%) & 70 \\
\hline Number of subjects & 70 & $40(57 \%)$ & - \\
Men & $21(30 \%)$ & $30(43 \%)$ & 0.001 \\
Women & $49(70 \%)$ & $30.14 \pm 9.29$ & 29 (3\%) \\
Age (mean \pm SE), years & $30.40 \pm 11.33$ & $15(21 \%)$ & 0.396 \\
Family history of KC & $15(21 \%)$ & $11(16 \%)$ & 0.24 \\
Consanguinity & $21(30 \%)$ & $1(1 \%)$ & $1 \times 10^{-6}$ \\
Atopy & $48(69 \%)$ & $50(71 \%)$ & $1 \times 10^{-6}$ \\
Eye rubbing & $56(80 \%)$ & $59(84 \%)$ & $1 \times 10^{-6}$ \\
UV exposure & $40(57 \%)$ & $27(39 \%)$ &
\end{tabular}

$\mathrm{KC}$, keratoconus; $P$, significance

The values are presented as the mean \pm standard error; the $P$-value for each comparison is calculated and is timed significant if it is superior than 0.05 .

Table 2. Details of the SNP used in the study

\begin{tabular}{llccc}
\hline Gene & db SNP ID & Assay ID & Location & Gene/Function \\
\hline IL4 & rs2070874 & C_16176215_10 & Chr.5: 132674018 & 5 Prime untranslated variant \\
FOXP3 & rs3761548 & C__27476877_10 & Chr.X: 49261784 & Intron variant
\end{tabular}

SNP, single nucleotide polymorphism; db SNP, single nucleotide polymorphism database; Chr, chromosome

Table 3. Genotypes and alleles distribution of IL4 rs2070874 and FOXP3 rs3761548 variants between keratoconus patients and control group

\begin{tabular}{|c|c|c|c|c|c|c|}
\hline Gene/SNP & Genotype/Allele & KC Patients $\mathrm{n}=70(\%)$ & Controls $n=70(\%)$ & $x^{2}$ & $P$-value & OR [Cl] \\
\hline \multirow[t]{7}{*}{ IL4 rs2070874 } & TT & $6(9)$ & $3(4)$ & 1.62 & 0.44 & - \\
\hline & $\mathrm{CC}$ & $43(61)$ & $49(70)$ & & & \\
\hline & $\mathrm{TC}$ & $21(30)$ & $18(26)$ & & & \\
\hline & $\mathrm{T}$ & $33(24)$ & 24 (17) & 1.78 & 0.18 & $0.67[0.37-1.21]$ \\
\hline & C & $107(76)$ & $116(83)$ & & & \\
\hline & $\mathrm{TT}+\mathrm{TC}$ & 27 (39) & $21(30)$ & 1.14 & 0.28 & $1.45[0.72-2.91]$ \\
\hline & $\mathrm{CC}$ & $43(61)$ & $49(70)$ & & & \\
\hline
\end{tabular}

\begin{tabular}{|c|c|c|c|c|c|c|}
\hline Gene/SNP & Genotype/Allele & KC Patients n = 70 (\%) & Controls $n=70(\%)$ & $x^{2}$ & $P$-value & OR $[\mathrm{Cl}]$ \\
\hline \multirow[t]{7}{*}{ FOXP3 rs3761548 } & $\mathrm{TT}$ & $12(17)$ & $12(17)$ & 0.03 & 0.98 & _ \\
\hline & GG & $32(46)$ & $33(47)$ & & & \\
\hline & GT & $26(37)$ & $25(36)$ & & & \\
\hline & $\mathrm{T}$ & $50(36)$ & $49(35)$ & 0.02 & 0.900 & 1.03 [0.63-1.68] \\
\hline & G & $90(64)$ & $91(65)$ & & & \\
\hline & $\mathrm{TT}+\mathrm{GT}$ & $38(54)$ & $37(53)$ & 0.03 & 0.86 & $1.06[0.55-2.05]$ \\
\hline & GG & $32(46)$ & $33(47)$ & & & \\
\hline
\end{tabular}

KC, keratoconus; P, significance; OR, odds ratio; $\mathrm{Cl}, 95 \%$ confidence interval 
thinning, Vogt's striae, ${ }^{[20]}$ and Fleischer's ring and topographic data. Patients previously grafted for one or both eyes were considered as cases.

All KC patients with AR reported having common classical symptoms mentioned in Allergic Rhinitis and its Impact on Asthma (ARIA) guidelines-2016 revision, ${ }^{[21]}$ as nasal itching, sneezing, rhinorrhea, and nasal congestion, and other $\mathrm{KC}$ patients stated that they already suffered from ocular symptoms as allergic rhinoconjunctivitis associated with itching and redness of the eyes and tearing.

The 70 control subjects had no ocular disease or previous eye surgeries and no family ocular history; all controls wearing glasses or suffering from myopia were excluded.

\section{DNA Extraction}

Eight $\mathrm{mL}$ peripheral blood was collected from patients and healthy controls using EDTA containing tubes and stored at $-20^{\circ} \mathrm{C}$ until analyses. Genomic DNA was extracted using the salting out method. ${ }^{[22]}$

\section{Genotyping of IL4 rs2070874 and FOXP3 rs3761548 Polymorphisms}

Molecular genotyping of SNPs was performed using TaqMan ${ }^{\circledR}$ SNP genotyping assay (Applied Biosystems Foster City, CA, USA) [Table 2] on qTOWER ${ }^{3}$ real-time polymerase chain reaction (PCR) machine (Analytik Jena, Germany). A $20 \mu \mathrm{L}$ $\mathrm{PCR}$ reaction contained $1 \mathrm{X}$ TaqMan $^{\circledR}$ genotyping master mix (Applied Biosystems Foster City, CA, USA), 1X SNP genotyping assay mix, and 20 ng DNA. PCR cycling parameters included predenaturation at $60^{\circ} \mathrm{C}$ for $30 \mathrm{sec}$, denaturation at $95^{\circ} \mathrm{C}$ for $10 \mathrm{sec}$, followed by 50 cycles of denaturation at $95^{\circ} \mathrm{C}$ for $15 \mathrm{sec}$ each, and finally annealing/extension at $60^{\circ} \mathrm{C}$ for $90 \mathrm{sec}$. The PCR products were measured at $60^{\circ} \mathrm{C}$ for $30 \mathrm{sec}$, which are proportional to the level of the fluorescence $\mathrm{VIC}^{\circledR}$ and $\mathrm{FAM}^{\circledR}$.

\section{Statistical Analysis}

The Hardy-Weinberg equilibrium (HWE) in the control group was calculated using Chi-square test. The comparison of quantitative variants between $\mathrm{KC}$ patients and control group, the frequencies of the allele and genotype were analyzed using the Pearson's Chi-square $\left(X^{2}\right)$ test. $P$-values $<0.05$ were considered significant. Risk was assessed by the odds ratios (ORs) and 95\% confidence intervals (Cls) were also estimated.

The genotype relative risk (GRR) method (a single genotype versus the others) was calculated to compare the genotype distribution in patients and controls. All the analyses were done using $2 \times 2$ contingency tables.

\section{RESULTS}

The demographic and other characteristics of all subjects are shown in Table 1. We first looked at the sex ratio; the gender distribution between patients and controls was found to be significantly different $\left(P=1 \times 10^{-3}\right)$. The mean age of KC patients was $30.40 \pm 11.33$ (range $6-70$ years), while the mean age of the healthy group was $30.14 \pm$ 9.29 (range, 19-62 years), there was no statically significant difference in the mean age between the two groups. Then, we were interested in the most discriminating risk factors; we observed a clear significant difference between cases and controls concerning atopy, eye rubbing with a high number of cases than controls also exposure to cigarette smoke as risk factor but with a large number of controls than cases $\left(P=1 \times 10^{-6}\right)$. KC patients had more family history of the pathology than healthy controls $\left(21 \%\right.$ vs $\left.3 \%, P=7 \times 10^{-4}\right)$. We also noted that there was no statistically significant difference between the case and control groups regarding the consanguinity and ultraviolet radiation (UV) exposure ( $P=0.24$ and 0.077 , respectively).

The distribution of allele frequencies for the two SNPs in control group did not deviate significantly from HWE $(P>0.05)$. The details of gentotypic and allelic frequencies are summarized in Table 3. The frequency distributions of IL4 rs2070874 genotypes between cases and controls revealed no statistical significance $(P=0.44)$. The allelic distribution of the polymorphism in the control population revealed that the allele $\mathrm{C}$ of IL4 rs2070874 represents the major allele (0.83) and the allele $T$ represents the allele minor $(0.17)$, there were no significant differences in the frequency's distribution of the IL4 rs2070874 C/T alleles ( $P=$ $0.18)$ even in the presence of at least one copy of the allele T of IL 4 rs2070874 among the genotypes $(P=0.28)$.

The distributions of genotype's frequencies of FOXP3 rs3761548 in KC cases were: GG, 46\%; GT, 
37\%; and TT, 17\%; and the distribution in control group were: GG, $47 \%$; GT, $36 \%$; and TT, $17 \%$. No significant association was observed between $\mathrm{KC}$ patients and healthy controls concerning FOXP3 rs3761548 genotypes $(P=0.98)$, the allele frequency distribution was also nonsignificant $(P$ $=0.9 ; \mathrm{OR}=1.03 ; 95 \% \mathrm{Cl}$ [0.63-1.68]), with minor $\mathrm{T}$ allele frequency 0.35 and major $G$ allele frequency 0.65 . The presence of at least one copy of the allele $\mathrm{T}$ of FOXP3 rs3761548 showed nonsignificant association between cases and controls $(P=0.86$; $\mathrm{OR}=1.06 ; 95 \% \mathrm{Cl}$ [0.55-2.05]).

\section{DISCUSSION}

We investigated the impacts of the most discriminating risk factors and IL4 rs2070874 and FOXP3 rs3761548 polymorphisms on a group of $\mathrm{KC}$ patients and controls from Western Algeria. To the best of our knowledge, this is the first study on the impact of IL4 and FOXP3 polymorphisms in a population originating from Algeria.

Our results showed a higher female prevalence in our study population $(P=0.001)$. This female predominance of $K C$ found in our sample is the opposite of what is found in the literature. Some studies have shown a male predominance among patients from the United States, ${ }^{[23]}$ while others have shown no significant difference. ${ }^{[24]}$ These results remain to be confirmed on a larger number of patients in order to be able to explain this female predominance in our population [Table 1].

The mean age in our sample of patients is equivalent to that found in several studies that demonstrate that KC usually affects adolescents at puberty as well as young adults until the fourth decade of life. ${ }^{[25]}$ The mean age of $K C$ cases in our study was $30.40 \pm 11.33$ years [Table 1], which fits perfectly with the study of Cozma et $\mathrm{al}^{[26]}$ concerning the White patient group in his work about the influence of ethnic origin on the incidence of $\mathrm{KC}$.

In our sample, there was a significant difference between cases and controls groups concerning family history with $\mathrm{KC}\left(P=7 \times 10^{-4}\right)$ [Table 1]. Indeed, the familial link with $K C$ represents a serious risk factor, ${ }^{[27]}$ since Gordon-Shaag et al showed that the risk of developing KC was 15 to 67 times higher compared to the general population. ${ }^{[28]}$ In addition, they reported that 5 to $27.9 \%$ of patients with $\mathrm{KC}$ had a positive family history. ${ }^{[28]}$
Consanguinity has also been proposed as a risk factor of $\mathrm{KC}$ in Israeli Arabs and Palestinian Arabs, ${ }^{[28-30]}$ as studies have shown that the high number of consanguineous marriages among Muslims is a cause of the increased incidence of KC. ${ }^{[31]}$ However, we did not find any significant difference between cases and controls in our population for this factor $(P=0.24)$ [Table 1]; this could be caused by the small number of $\mathrm{KC}$ patients group.

For more than 50 years, atopy has been identified as a risk factor. ${ }^{[32]}$ In addition, several studies have shown that asthma and allergy are associated with $\mathrm{KC}$ with statistical significance $\left(P=0.0008\right.$ for asthma and 0.04 for allergy) ${ }^{[7]}$ Our results correlate with this work since in our sample, atopy was reported in $69 \%$ of cases compared to $16 \%$ in controls with a statistically significant difference $\left(P=1 \times 10^{-6}\right)$ [Table 1], knowing that all patients are from Western Algeria - a coastal region known for its humid and marine climate and neighboring industrial areas. A study in the region of Eastern Algeria confirmed that climatology would increase the risk of developing allergic diseases, and atopy based on family criteria was very common in this population. ${ }^{[33]}$

Another risk factor is related to patients' habits, the eye rubbing. The rubbing of the eyes is currently the most important risk factor that is clearly identified. This risk factor triggers the onset and progression of the disease through several effects, including the stimulation of inflammation. Most authors report that approximately half of the $\mathrm{KC}$ patients rub their eyes, although this varies with the usual duration of rubbing and that the rubbing of the eyes is mild or vigorous. ${ }^{[28,34]}$ The results of our study are in perfect correlation with the literature. We have shown that $80 \%$ of patients with $\mathrm{KC}$ rubbed their eyes regularly compared to $1 \%$ in controls. Thus, in our sample, eye rubbing seems to be associated with the appearance of the $\mathrm{KC}\left(P=1 \times 10^{-6}\right)$ [Table 1]. Indeed, several studies have attempted to explain the involvement of this risk factor in the development of KC. In fact, the micro-trauma caused to the epithelium by the eye rubbing generates high levels of matrix metalloproteases (MMP-1 and MMP-13) secreted by the epithelial and stromal cells, in addition, the release of inflammatory mediators (IL- 6 and TNF$\alpha)$ is one of the processes leading to $K C$ and its progression. ${ }^{[35]}$ 
In our sample, we found that there was no statistically significant difference between the case and control groups concerning sun exposure risk factor $(P=0.07)$ [Table 1]. Studies have shown that the prevalence of $\mathrm{KC}$ is higher in sunny countries than in Europe or North America, high sun exposure in these countries would explain the high prevalence of $\mathrm{KC} .^{[27]}$ In addition to the genetic component, UV light has an additive effect by causing oxidative damage which would be among the causes of the acceleration of the pathological process of KC. ${ }^{[28]}$ However, it should be noted that UV could provide, at a controlled dose, a beneficial effect by inducing the reticulation of corneal collagen, thus attenuating the development or progression of the disease. ${ }^{[36]}$

In 2008, a study was able to demonstrate for the first time that cigarette smoking appeared to have a protective effect against $K C .{ }^{[37]}$ Our results seem to support this hypothesis, since in our sample, we observed a greater frequency of smoking in controls (84\%) compared to KC patients (39\%). Moreover, this difference is statistically significant $\left(P=1 \times 10^{-6}\right)$ [Table I], and exposure to cigarette smoke appears to have a protective effect (OR $=0.1$ [0.055-0.269]). Other studies concluded that there was no significant association between smoking and $\mathrm{KC} .^{[30]}$

The hypothesis of testing the effect of the IL4 rs2070874 and FOXP3 rs3761548 polymorphisms in the predisposition to $\mathrm{KC}$ development is based on the fact that these polymorphisms known to be associated with allergies could be either directly associated with the development of $\mathrm{KC}$ or indirectly, via inflammation induced by microtrauma due to eye rubbing. ${ }^{[34]}$ Indeed, our results [Table 1] showed that atopy and eye rubbing in patients with $\mathrm{KC}$ were significantly associated with the pathology in our study sample $\left(P=1 \times 10^{-6}\right)$ [Table 1].

According to our results, the T allele of IL4 rs2070874 represents the minor allele (0.17) [Table 3]. This allelic distribution is close to the findings of a study performed in 2018 on a sample of 58 subjects in the Western Algeria (0.10). ${ }^{[38]}$ The same observation was reported in other populations such as Italians (0.12), ${ }^{[39]}$ Swedish, Australian, Finnish, and English populations (0.16). ${ }^{[40]}$ This frequency is lower than that reported in the AfricanAmericans $(0.43)^{[41]}$ and Indians (0.39). ${ }^{[42]}$ However, the $\mathrm{T}$ allele of FOXP3 rs3761548 represents the minor allele with a frequency of 0.35 [Table 3].
This minor allele frequency (MAF) is in line with the Egyptian study (0.34), ${ }^{[4]}$ but different from those reported in Turkish and Indian populations, 0.61 and 0.56 , respectively. ${ }^{[4,45]}$ This variability in the results of the studies may be due to ethnic factors and the size of the sample studied [Table 3].

Our case-control study suggests no association between (IL4 rs2070874, FOXP3 rs3761548) polymorphisms and susceptibility to $\mathrm{KC}$, even in the presence of at least one copy of the allele $T$ of IL4 rs2070874 or T allele of FOXP3 rs3761548 [Table 3]. According to Bawazeer et al, ${ }^{[34]}$ allergy is indirectly associated with the development of $\mathrm{KC}$ and its effect is probably due to inflammation caused by rubbing eye movements. These results, once confirmed in a larger cohort, would be further evidence. ${ }^{[34]}$ Indeed, most authors report that about half of the patients with $\mathrm{KC}$ rub their eyes regularly, although the percentage varies among studies. ${ }^{[28]}$ It is interesting to note that in cases of asymmetric $\mathrm{KC}$, the most affected eye has been rubbed the most vigorously. ${ }^{[46]}$ Coyle et al reported the case of an 11-year-old boy who at the age of 5 , discovered that he could stop his tachycardia by vigorously massaging his left eye (up to $20 \mathrm{~min} /$ day). ${ }^{[4]}$ At age 7, he hadn't developed anything in his eyes. At the age of 11 , the child developed unilateral KC in only his left eye which was massaged vigorously. Another case of $\mathrm{KC}$ has been reported in a patient with a history of vigorous daily massage of the left eye which led to unilateral $\mathrm{KC}$ in that eye only. ${ }^{[48]} \mathrm{A}$ series of cases confirms the asymmetrical expression of the disease in patients who usually rub the most affected eye. ${ }^{[46,49,50]}$

Thus, eye rubbing would cause micro-trauma leading to the secretion of high levels of MMP. ${ }^{[35]}$ These factors can lead to progression of $\mathrm{KC}$ associated with apoptosis of keratocytes, ${ }^{[51]}$ and atopic episodes can contribute and interact with other inflammatory processes related to KC. ${ }^{[52]}$

This is the first demonstration of the implication of susceptibility genes to allergy in the development of $\mathrm{KC}$, and this is the first time that the IL4 and FOXP3 genes association was analyzed with $\mathrm{KC}$ risk in an Algerian population.

Our results showed that there would be a significant association in our study sample between risk factors such as family history with disease, atopy and eye rubbing, and $\mathrm{KC}$ development. In addition, our results confirmed 
that smoking would provide a protective effect against the pathology. However, it has been shown that there is no association between the IL4 rs2070874 and FOXP3 rs3761548 polymorphisms and the occurrence of $\mathrm{KC}$ in the population of Western Algeria. However, because of the moderate size of the sample, the statistical power of the present study was relatively low, being $50 \%$ and $59 \%$ for the IL4 rs2070874 and FOXP3 rs3761548 polymorphisms, respectively.

In summary, our results provide precise and upto-date information on the association of the two polymorphisms studied with KC in the population of Western Algeria. The small size of our study requires a replication of the results in a larger sample of the population in order to confirm or affirm the association. Nevertheless, the present study does not exclude the effect of IL 4 and FOXP3 gene polymorphisms in the pathophysiological process of the $\mathrm{KC}$ disease. For this reason, the present study may be considered as a pilot study.

\section{Financial Support and Sponsorship}

Nil.

\section{Conflicts of Interest}

There are no conflicts of interest.

\section{REFERENCES}

1. Krachmer JH, Feder RS, Belin MW. Keratoconus and related noninflammatory corneal thinning disorders. Surv Ophthalmol 1984;28:293-322.

2. Lema I, Sobrino T, Durán JA, Brea D, Díez-Feijoo E. Subclinical keratoconus and inflammatory molecules from tears. Br J Ophthalmol 2009;93:820-824.

3. Jun AS, Cope L, Speck C, Feng X, Lee S, Meng $H$, et al. Subnormal cytokine profile in the tear fluid of keratoconus patients. PLOS ONE 2011;6:e16437.

4. Davidson AE, Hayes S, Hardcastle AJ, Tuft SJ. The pathogenesis of keratoconus. Eye Lond Eng/ 2014;28:189195.

5. Harrison RJ, Klouda PT, Easty DL, Manku M, Charles J, Stewart CM. Association between keratoconus and atopy. Br J Ophthalmol 1989;73:816-822.

6. McMonnies CW, Boneham GC. Keratoconus, allergy, itch, eye-rubbing and hand-dominance. Clin Exp Optom 2003;86:376-384.

7. Nemet AY, Vinker S, Bahar I, Kaiserman I. The association of keratoconus with immune disorders. Cornea 2010;29:1261-1264.
8. Bijlsma FJ, van Kuik J, van Hoffen $\mathrm{E}$, de Jonge $\mathrm{N}$, Tilanus MGJ, Gmelig-Meyling FHJ, et al. Acute cardiac transplant rejection is associated with low frequencies of interleukin-4 producing helper T-Lymphocytes rather than with interleukin-4 promoter or splice variants. Hum Immunol 2002;63:317-323.

9. Vijayanand P, Seumois G, Simpson LJ, Abdul-Wajid S, Baumjohann D, Panduro M, et al. Interleukin-4 production by follicular helper $T$ cells requires the conserved 114 enhancer hypersensitivity site V. Immunity 2012;36:175187.

10. Harada $\mathrm{Y}$, Tanaka S, Motomura $\mathrm{Y}$, Harada $\mathrm{Y}$, Ohno S, Ohno S, et al. The $3^{\prime}$ enhancer CNS2 is a critical regulator of interleukin-4-mediated humoral immunity in follicular helper T cells. Immunity 2012;36:188-200.

11. Movahedi M, Amirzargar AA, Nasiri R, Hirbod-Mobarakeh A, Farhadi E, Tavakol M, et al. Gene polymorphisms of interleukin-4 in allergic rhinitis and its association with clinical phenotypes. Am J Otolaryngol 2013;34:676-681.

12. Gervaziev YV, Kaznacheev VA, Gervazieva VB. Allelic polymorphisms in the interleukin-4 promoter regions and their association with bronchial asthma among the Russian population. Int Arch Allergy Immunol 2006;141:257-264.

13. Suzuki I, Hidaka N, Yamaguchi E, Kawakami Y. Association between a $\mathrm{C}+33 \mathrm{~T}$ polymorphism in the IL-4 promoter region and total serum IgE levels. Clin Htmlent Glyphamp Asciiamp Exp Allergy 2000;30:1746-1749.

14. Yang $\mathrm{H}-\mathrm{J}$. Association between the interleukin-4 gene $\mathrm{C}$ 589T and C+33T polymorphisms and asthma risk: a metaanalysis. Arch Med Res 2013;44:127-135.

15. Denyer MP, Pinheiro DY, Garden OA, Shepherd AJ. Missed, not missing: phylogenomic evidence for the existence of avian FOXP3. Pappalardo F, éditeur. PLoS ONE 2016;11:e0150988.

16. Maruyama T, Konkel JE, Zamarron BF, Chen W. The molecular mechanisms of FOXP3 gene regulation. Semin Immunol 2011;23:418-423.

17. Zhang L, Zhang Y, Desrosiers M, Wang C, Zhao Y, Han D. Genetic association study of FOXP3 polymorphisms in allergic rhinitis in a Chinese population. Hum Immunol 2009;70:930-934.

18. Fodor E, Garaczi E, Polyánka H, Koreck A, Kemény L, Széll M. The rs3761548 polymorphism of FOXP3 is a protective genetic factor against allergic rhinitis in the Hungarian female population. Hum Immunol 2011;72:926-929.

19. World Medical Association. World Medical Association Declaration of Helsinki: Ethical Principles for Medical Research Involving Human Subjects. JAMA 2013;310:2191-2194.

20. Hollingsworth JG, Efron N. Observations of banding patterns (Vogt Striae) in keratoconus: a confocal microscopy study. Cornea 2005;24:162-166.

21. Brożek JL, Bousquet J, Agache I, Agarwal A, Bachert C, Bosnic-Anticevich S, et al. Allergic Rhinitis and Its Impact on Asthma (ARIA) guidelines - 2016 revision. J Allergy Clin Immunol 2017;140:950-958.

22. Miller SA, Dykes DD, Polesky HF. A simple salting out procedure for extracting DNA from human nucleated cells. Nucleic Acids Res 1988;16:1215.

23. Kennedy RH, Bourne WM, Dyer JA. A 48-year clinical and epidemiologic study of keratoconus. Am J Ophthalmol 1986;101:267-273. 
24. Li X, Rabinowitz YS, Rasheed K, Yang H. Longitudinal study of the normal eyes in unilateral keratoconus patients. Ophthalmology 2004;111:440-446.

25. Rabinowitz YS. Keratoconus. Surv Ophthalmol 1998;42:297-319.

26. Cozma I, Atherley C, James NJ. Influence of ethnic origin on the incidence of keratoconus and associated atopic disease in Asian and White patients. Eye 2005;19:924925.

27. Moussa S, Grabner G, Ruckhofer J, Dietrich M, Reitsamer $\mathrm{H}$. Genetics in keratoconus - what is new? Open Ophthalmol J 2017;11:201-210.

28. Gordon-Shaag A, Millodot M, Shneor E, Liu Y. The genetic and environmental factors for keratoconus. BioMed Res Int 2015;2015:795738.

29. Barbara R, Gordon-Shaag A, Millodot M, Shneor E, Essa M, Anton M. Prevalence of keratoconus among young Arab students in Israel. Int J Keratoconus Ectatic Corneal Dis 2014;3:9-14.

30. Gordon-Shaag A, Millodot M, Essa M, Garth J, Ghara M, Shneor E. Is consanguinity a risk factor for keratoconus? Optom Vis Sci 2013;90:448-454.

31. Georgiou T, Funnell CL, Cassels-Brown A, O'Conor R. Influence of ethnic origin on the incidence of keratoconus and associated atopic disease in Asians and White patients. Eye 2004;18:379-383.

32. Galvis V, Sherwin T, Tello A, Merayo J, Barrera R, Acera A. Keratoconus: an inflammatory disorder? Eye 2015;29:843-859.

33. Boumendjel A, Tridon A, Ughetto S, Messarah M, Salah Boulakoud M. Environnement allergénique d'une population d'enfants asthmatiques à Annaba (Algérie). Ann Biol Clin (Paris) 2010;68:317-324.

34. Bawazeer AM, Hodge WG, Lorimer B. Atopy and keratoconus: a multivariate analysis. $\mathrm{Br} \mathrm{J}$ Ophthalmol 2000;84:834-836.

35. Balasubramanian SA, Pye DC, Willcox MD. Effects of eye rubbing on the levels of protease, protease activity and cytokines in tears: relevance in keratoconus: eye rubbing in keratoconus. Clin Exp Optom 2013;96:214-218.

36. Chan E, Snibson GR. Current status of corneal collagen cross-linking for keratoconus: a review: cross-linking and keratoconus. Clin Exp Optom 2013;96:155-164.

37. Spoerl E, Raiskup-Wolf F, Kuhlisch E, Pillunat LE. Cigarette smoking is negatively associated with keratoconus. $J$ Refract Surg 2008;24:S737-S740.

38. Rahmoun N, El Mecherfi KE, Bouchetara A, Lardjem Hetraf S, Dahmani Amira C, Adda Neggaz L, et al. Association of REL polymorphism with cow's milk proteins allergy in pediatric Algerian population. Fetal Pediatr Pathol 2018;37:74-83.

39. Vargiolu M, Silvestri T, Bonora E, Dolzani P, Pulsatelli L, Addimanda $\mathrm{O}$, et al. Interleukin-4/interleukin-4 receptor gene polymorphisms in hand osteoarthritis. Osteoarthr Cartil 2010;18:810-816.

40. FitzGerald LM, Zhao S, Leonardson A, Geybels MS, Kolb $\mathrm{S}$, Lin DW, et al. Germline variants in IL4, MGMT and AKT1 are associated with prostate cancer-specific mortality: an analysis of 12,082 prostate cancer cases. Prostate Cancer Prostatic Dis 2018;21:228-237.

41. Battle NC, Choudhry S, Tsai H-J, Eng C, Kumar G, Beckman $\mathrm{KB}$, et al. Ethnicity-specific gene-gene interaction between IL-13 and IL-4R $\alpha$ among African Americans with asthma. Am J Respir Crit Care Med 2007;175:881-887.

42. Majumder P, Panda SK, Ghosh S, Dey SK. Interleukin gene polymorphisms in chronic periodontitis: a casecontrol study in the Indian population. Arch Oral Biol 2019;101:156-164.

43. Elsohafy M, Elghzaly A, Abdelsalam H, Gaballah M. Assessment of the possible role of FOXP3 gene (rs3761548) polymorphism in psoriasis vulgaris susceptibility and pathogenesis: Egyptian study. Indian Dermatol Online J2019;10:401.

44. Cekin N, Pinarbasi E, Bildirici AE, Donmez G, Oztemur $Z$, Bulut O, et al. FOXP3 rs3761548 polymorphism is associated with knee osteoarthritis in a Turkish population. Int J Rheum Dis 2018;21:1779-1786.

45. Jahan P, Ramachander VRV, Maruthi G, Nalini S, Latha KP, Murthy TSR. FOXP3 promoter polymorphism (rs3761548) in breast cancer progression: a study from India. Tumor Biol 2014;35:3785-3791.

46. Zadnik K, Steger-May K, Fink BA, Joslin CE, Nichols $\mathrm{JJ}$, Rosenstiel CE, et al. Between-eye asymmetry in keratoconus. Cornea 2002;21:671-679.

47. Terrence Coyle J. Keratoconus and eye rubbing. Am J Ophthalmol 1984;97:527-528.

48. Gritz DC, McDonnell PJ. Keratoconus and ocular massage. Am J Ophthalmol 1988;106:757-758.

49. Jafri B, Lichter $\mathrm{H}$, Stulting RD. Asymmetric keratoconus attributed to eye rubbing. Cornea 2004;23:560-564.

50. Koenig SB. Bilateral recurrent self-induced keratoconus. Eye Contact Lens Sci Clin Pract 2008;34:343-344.

51. Rehany U, Lahav M, Shoshan S. Collagenolytic activity in keratoconus. Ann Ophthalmol 1982;14:751-754.

52. McMonnies CW. Inflammation and keratoconus. Optom Vis Sci Off Publ Am Acad Optom 2015;92:e35-e41. 